\title{
PROCEDIMENTOS INTERCULTURAIS E DIVERSIDADE ÉTNICO-RACIAL DO BRASIL EM DOIS LIVROS DIDÁTICOS DE PORTUGUÊS PARA ESTRANGEIROS
}

\section{Lucia Maria de Assunção BARBOSA*}

- RESUMO: Neste artigo objetivamos discutir em que medida o conceito de interculturalidade está presente em dois livros didáticos de Português língua estrangeira, produzidos no Brasil e de que forma estão caracterizados diferentes grupos étnicos partícipes da cultura brasileira. Tomamos como princípio norteador a educação intercultural que preconiza o desenvolvimento de uma compreensão e de um reconhecimento não apenas das culturas em contato, no contexto de ensino-aprendizagem de línguas, mas das diferenças existentes entre elas.

- PALAVRAS-CHAVE: Interculturalidade. Português para estrangeiros. Livro didático. Diversidade étnico-racial. Representação.

No contexto de ensino-aprendizagem de uma nova língua-cultura, o conceito de interculturalidade indica-nos possibilidades de aproximaçóes entre essas duas dimensóes. Trata-se de uma forma de mediação cultural da qual o aprendente participa, ao mesmo tempo em que reflete sobre sua cultura de origem e sobre a cultura da qual quer fazer parte. Essa reflexáo ocorre, sobretudo, nas interaçóes sociais cotidianas com a cultura que se pretende conhecer, quando o aprendente percebe, aos poucos, que apenas o domínio de aspectos linguisticos não é suficiente para ter acesso ao que Edward Hall (1971) denomina dimensóes ocultas.

Em pesquisas anteriores, o mesmo autor chama a atenção para uma análise compreensiva entre comunicação e cultura. Preocupado com as dificuldades (causadas por diferenças culturais) encontradas por americanos enviados em missóes a outros países, o autor propôs estudos, de caráter transcultural, que auxiliassem a prática cultural dessas pessoas que se deslocavam para outros países. Em seus estudos, o autor destaca, por exemplo, as diferentes formas de se administrar o tempo e demonstra que a cultura está impregnada no ser humano mais do que podemos imaginar e perceber, pois, segundo ele, essa dimensão está vinculada, na maior parte do tempo, a realidades ocultas que escapam de nosso controle, mas que constituem a trama da existência humana.

\footnotetext{
* UnB - Universidade de Brasília. Instituto de Letras - Departamento de Línguas Estrangeiras e Tradução. Brasília - DF - Brasil. 70910-900 - luciunb@gmail.com
} 
Tais realidades englobam, dentre outros aspectos, os rituais, os códigos, as representaçóes e os estereótipos que fazem parte de uma sociedade e, portanto, em alguma medida caracterizam-na e identificam-na. Aprender a decifrar essas mensagens veladas ainda constitui um desafio, principalmente no domínio do ensino e da aprendizagem de língua estrangeira, uma vez que exige um esforço tanto de quem ensina quanto de quem aprende.

Para as reflexões acerca de aspectos culturais e educação intercultural no contexto de ensino-aprendizagem de línguas, retomaremos pesquisas empreendidas por AbdallahPretceille (1996a, 1996b), Byram (1992), Galisson (1995a, 1995b), Porcher (1986, 1988), De Carlo (1998), Almeida Filho (2002), Collès (2006), Barbosa (2007a, 2007b, 2008), Bolognini (1991).

De acordo com Abdallah-Pretceille (1996b), o traço marcante da educação intercultural é a sua imbricação com os problemas sociais. Desse modo, segundo a autora, um trabalho que preveja relações entre culturas baseia-se sobre o não-dito e sobre o reconhecimento do outro e de si mesmo. Sob essa perspectiva, a interculturalidade não é uma competência que aprendente e professor deverão ter, mas será um fator que agirá de forma complementar às competências linguística e cultural. Ressalta ainda a autora que o estudo e a prática em torno dessa abordagem reenviam tanto a níveis filosóficos, psicológicos, antropológicos quanto ao contexto social, político, econômico e, às vezes, ideológico (ABDALLAH-PRETCEILLE, 1996b). Níveis psicológicos porque tudo o que se refere às relações humanas está intrinsecamente ligado às estruturas da personalidade e a problemas individuais; antropológicos porque há referências constantes às questóes de identidade cultural, à cultura, bem como às noçóes correlatas a elas como gênero e raça, por exemplo.

Além desses argumentos, há que se considerar o fator dinâmico que caracteriza tanto a cultura quanto a identidade. Ao considerarmos a elasticidade de sentidos que esses dois termos englobam, desvencilhamo-nos da ideia de que a cultura não pode ser considerada o denominador comum das atividades, das ideias, das atitudes dos membros de uma sociedade.

Se tomarmos o contexto de ensino-aprendizagem de línguas, não podemos nos contentar em mostrar uma cultura como um objeto estático, cristalizado, situado fora do tempo e do espaço. Além disso, como ressalta Abdallah-Pretceille (1996b), a perspectiva intercultural apresenta-se como uma alternativa metodológica rica em potencialidades educativas, uma vez que ela se apoia na noção de alteridade enquanto eixo conceitual e metodológico. Desse modo, a finalidade de uma educação que se queira intercultural é desenvolver atitudes de compreensão e de respeito entre culturas diferentes.

Não se trata, pois, de uma abordagem sobre a língua, sobre a cultura ou sobre as instituiçōes deste ou daquele país, trata-se de elaborar reflexóes e açóes que nos permitam reconhecer práticas culturais como entidades dinâmicas, moventes, instáveis e, por consequência, em permanente alteração. Tais características impóem 
limites no modo como apreenderemos e analisaremos essas culturas (ABDALLAHPRETCEILLE, 1996b). Desse modo, os monumentos, as obras de arte, a literatura, a culinária, a arquitetura, por exemplo, não serão tomados como um cenário que oculta valores culturais veiculados pelos indivíduos e grupos de uma dada sociedade. Eles são elementos desencadeadores de uma rede de significaçóes complexa e específica para cada participante dessa cultura ou dessas culturas.

Para De Carlo (1998), uma educação intercultural preconiza dois objetivos: a) auxiliar os aprendentes a vencerem a insegurança inicial causada pelo que lhes é desconhecido; b) incentivá-los a generalizar as experiências de contato com a cultura estrangeira, sem, no entanto, cair na armadilha do estereótipo. Ao interpretar o sistema do outro, também fazemos uma reflexão sobre o nosso sistema, pois apesar das diferenças (mas também graças a elas!) é possível que, ao percebermos um costume diferente, acabamos por reconhecermos (pelo contraste) nossos hábitos e costumes, em um movimento espiral.

A esses objetivos, acrescentamos os estudos de Collès (2006) para quem uma formação intercultural deve ter como propósito favorecer e sustentar o pluralismo cultural; trabalhar para a instauração de uma sociedade fundada nos princípios da igualdade e contribuir para o estabelecimento de relaçóes étnico-raciais baseadas no respeito e no reconhecimento.

A interculturalidade, mais do que uma competência, pode ser tomada como um procedimento (ou uma ação) que auxilia o aprendente na percepção das configuraçóes identitárias e culturais de forma problematizada e não-simplificada. Nos dias atuais, em que vemos como eixos de debates reivindicaçóes para que se que efetivem políticas públicas de reconhecimento de diferenças e especificidades de minorias, a interculturalidade pode ser uma escolha pragmática para negociação e mediação dessa convivência baseada no respeito mútuo.

A partir dessas reflexóes do que caracteriza uma ação intercultural, interrogamonos sobre como livros didáticos têm possibilitado o exercício desses procedimentos interculturais. Nosso interesse específico por esse material justifica-se pelo fato de o considerarmos o locus de diferentes modos de representaçáo do Outro, seja como peça ilustrativa (por meio de imagens) seja por meio de excertos textuais. Essas representaçóes produzem significados e identidades que podem congelar não apenas nossa visão desse Outro, mas reforçar generalizaçóes.

No caso específico de português para estrangeiros, perguntamo-nos quais são as percepçóes da sociedade brasileira que ficam evidenciadas nos livros didáticos? Nos últimos dez anos, pesquisadores brasileiros de diferentes áreas têm empreendido estudos dedicados às imagens e representações de negros e de indígenas em livros didáticos, na publicidade e na mídia, por exemplo. Entretanto, no que se refere especificamente ao contexto de ensino-aprendizagem do português língua-estrangeira ou segunda língua, na sua modalidade brasileira, a diversidade étnico-sócio-cultural tem sido tema pouco discutido. 
Uma observação mais demorada dos livros didáticos de português para estrangeiros mostra-nos que há um predomínio de elementos gramaticais e que os textos referentes à cultura tendem a mostrar aspectos generalizadores, privilegiando uma visão homogênea do que seja o Brasil e os brasileiros.

A partir desta perspectiva, pretendemos analisar como a cultura brasileira (ou as culturas brasileiras) vem sendo veiculada em alguns livros didáticos de português, produzidos no Brasil, destinados a estrangeiros e em que medida as atividades propostas auxiliam o aprendente a (re)conhecer a diversidade étnico-racial, enquanto premissa para sua compreensão e, consequentemente para a desconstrução de estereótipos sobre o país.

O engajamento proposto por Porcher (1986) serve-nos de contraponto para uma análise de alguns componentes de um contexto cultural tão complexo como o do Brasil. Segundo o autor, trata-se de estabelecer um processo metodológico que abandone as visões estereotipadas do país, baseadas sobretudo em impressionismos simplificadores das suas realidades sociológicas, históricas, antropológicas e culturais. Esta é, a nosso ver, uma necessidade concreta diante dos riscos, sempre presentes, de se tomar como base generalizaçóes capazes de reforçar estereótipos calcados, na sua grande maioria em exotismos.

Para verificar em que medida os manuais de português para estrangeiros retratam o Brasil e os brasileiros e, sobretudo, como o fazem, partimos da concepção de que o ato de aprender não pode ser entendido como uma prática instrumental, pois esta implica desprovimento das práticas sociais ou das intervençóes subjetivas. Em um contexto educativo mais amplo, o aprendizado de uma língua pressupóe aprender a comunicarse com aqueles que pertencem a outras culturas, reconhecendo e respeitando os princípios fundadores das suas identidades (ZARATE, 1986).

Desse modo, ainda, segundo Abdallah-Pretceille (1996b), o ato de comunicação pressupóe uma interação, um movimento em direção ao outro, portanto, caracterizase pelo processo dialógico carecendo de ajustes permanentes em função das situaçôes e das interlocuçóes. Trata-se, pois, mais de uma compreensão do outro (dimensão antropológica) do que de um mero conhecimento (dimensão etnográfica).

Outro fator que nos parece imprescindível observar está relacionado ao conceito de competência cultural, cujo objetivo náo pode ser apenas o de saber sobre uma dada cultura, mas saber orientar-se na cultura do outro. Essa competência é a capacidade que o aprendente tem de antecipar ou de interpretar, em uma dada situação, o que vai se passar ou quais comportamentos convém ter para estabelecer uma relação adequada com os protagonistas da situação (PORCHER, 1988).

Ao almejarmos essa competência, devemos ter em mente que o estudo exaustivo de fatos gramaticais não é suficiente para chegarmos a uma competência cultural, pois esta pressupóe uma cultura-em-ato em oposição a uma cultura-objeto. (ABDALLAHPRETCEILLE, 1996b). 
Entretanto, conforme assinala Beacco (2000), o que se observa com muita frequência nos materiais didáticos (e nas práticas relacionadas ao ensino de língua estrangeira) é uma hierarquização entre língua e cultura, com uma sobreposição da primeira sobre a segunda, na qual as dimensóes culturais tendem a aparecer apenas como um saber enciclopédico. Essas ocorrências podem levar a uma visão fragmentada e pontual da cultura em estudo e impossibilitar uma reflexão mais aprofundada e organizada sobre os diferentes grupos sociais nela existentes.

Desse modo, faz-se necessário que os aprendentes tenham acesso a uma série de conteúdos que lhes deem condiçôes de ultrapassar os níveis de observação e de descrição dos traços culturais e estabelecer formas de religá-los a um dado histórico, situá-los em um contexto socioeconômico para, finalmente, relativizar e interpretar as dimensões culturais.

Esta perspectiva servir-nos-á de guia, no que concerne à presença dos conteúdos culturais nos livros didáticos, para indagarmos até que ponto esses conteúdos colaboram para uma compreensão da cultura brasileira.

Nossa investigação é de base qualitativa, pois entendemos que as pesquisas qualitativas caracterizam-se como um recurso metodológico largamente utilizado nas áreas de ciências humanas e pelo fato de que a seleçáo da amostra obedece a critérios de representatividade.

O nosso corpus é composto pelos livros didáticos Avenida Brasil (reimpressão de 2006) e Bem-Vindo! A língua portuguesa no mundo da comunicação: Português para estrangeiros (edição do ano 2000). O nosso critério de escolha baseou-se no fato de que os dois manuais têm sido sistematicamente reeditados e atualizados o que, para nós, são indicadores de sucesso na comercialização.

O livro didático Avenida Brasil traz no seu texto de apresentação (LIMA et al., 2006, p.3) as seguintes observações:

Avenida Brasil não se expande apenas a partir da mera seleção de intençôes de fala e de estrutururas. Ele vai além. Informaçôes e consideraçôes sobre o Brasil, sua gente e seus costumes permeiam o material, estimulando a reflexão intercultural. Desse modo, enquanto adquire instrumentos para a comunicação, o aluno encontra, também elementos para conhecer e compreender o Brasil e os brasileiros.

A partir da leitura desse texto de apresentação, fica explícita a intenção de se fazer "uma reflexão intercultural" e também de mostrar elementos que permitam que o aprendente ultrapasse o nível de conhecimento para "compreender o Brasil e os brasileiros", conforme preconiza a prática de uma educação baseada nos princípios da interculturalidade.

Ao procedermos a uma análise de aspectos referentes às dimensóes culturais brasileiras, constatamos que o manual privilegia ora aspectos geográfico-históricos, ora outros relativos à cultura do tipo erudito (biografias de artistas e reproduçóes de 
obras de arte de artistas plásticos e escultores brasileiros, trechos de obras de escritores considerados representativos). Aparecem, igualmente, textos referentes ao povo brasileiro, provérbios e dados estatísticos de diversos assuntos relativos ao país.

O livro apresenta uma quantidade significativa de textos autênticos como formulários, cardápios, notícias de jornal, publicidade, anúncios, cartas, bilhetes, reproduçóes de obras de arte que podem ser tomados como ponto de partida para um trabalho efetivo com as dimensóes culturais sob diferentes aspectos. Avaliamos de forma positiva o fato de o manual propor diferentes gêneros textuais, uma vez que estes podem sugerir modos de compreensão diferenciados de aspectos relativos à cultura brasileira.

Entretanto, embora os autores afirmem que irão privilegiar aspectos interculturais, a opção restringe-se a fazer comparaçóes entre culturas, com perguntas do tipo: "Como é no seu país?" Entendemos que a comparação é inevitável, no entanto, se permanecermos nos dados que ela sugere, corremos o risco de reforçar estereótipos e representaçóes superficiais da cultura-alvo.

No que se refere a regióes brasileiras, o manual apresenta locais típicos, com imagens de praia, mar, barquinhos e outras ilustraçóes que mais se assemelham a cartóes postais (BOLOGNINI, 1991) e reforçam a ideia de paraíso tropical, explorado, com frequência, pela publicidade ligada ao turismo brasileiro.

Concernente à diversidade étnico-racial brasileira, o manual trabalha com a idéia de influências típicas da população indígena e da população negra (culinária, língua, religiáo, música, raça, dia-dia), baseadas no livro Casa Grande e Senzala, de Gilberto Freyre (1984), obra que marcou a exaltação do mito da democracia racial brasileira. Segundo esse mito, o Brasil construiu uma sociedade multirracial (brancos, negros e indígenas) com base na convivência harmoniosa e na ausência de conflitos entre as três raças, de cujas influências nos orgulhamos. (Figura 1). 
Figura 1 - Influências na cultura brasileira

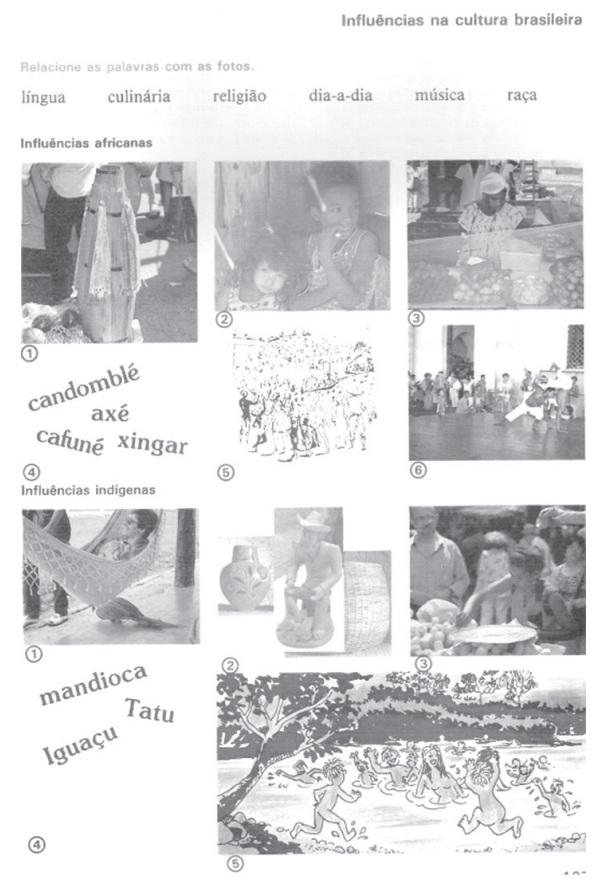

Fonte: Lima et al. (2006, v.1, p.127).

Os exercícios que se seguem a essa ilustração não abrem espaços para discussão sobre modos de vida dessas populaçóes nos dias atuais, tampouco das lutas de resistência e conquistas efetivadas por elas.

Ainda a respeito da diversidade étnico-racial dos brasileiros, observamos que ocorre um apagamento da presença desses dois grupos (negros e indígenas) nos volumes $1 \mathrm{e}$ 2 dessa coleção. A figura 2 do anexo, mostra um grupo de pessoas despidas tomando banho em um rio (que supomos sejam indígenas) para ilustrar a influência desse grupo em nossos hábitos diários.

Com referência à população negra, nos dois volumes, o número de imagens é insignificante quando comparado à representação da população branca. Nesse aspecto, vemos repetir inadequaçóes apontados em pesquisas brasileiras, no que se refere especificamente à ausência de diferentes grupos sociais brasileiros e de suas realidades e especificidades.

Segundo essas pesquisas, negros e indígenas ainda estão subrepresentados nos manuais didáticos brasileiros. Quando presentes, exercem funçóes ou atividades pouco valorizadas pela sociedade. A exemplo disso, a figura 2, apresenta o cotidiano de duas mulheres brasileiras (uma branca e uma negra) que possuem ocupações bastante diferenciadas: a mulher branca é professora e mulher negra é empregada doméstica. 
Figura 2-O dia-a-dia de duas brasileiras

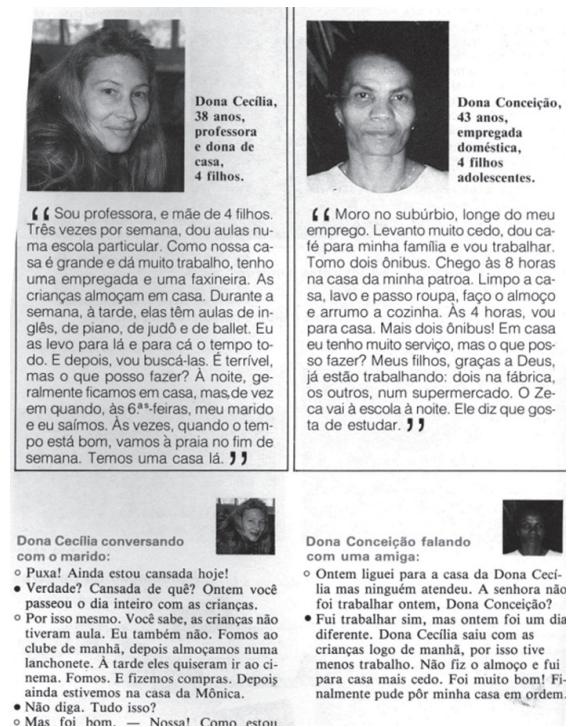

Fonte: Lima et al. (2006, v.1, p.50).

Esta lição 6 tem por título "O dia-a-dia de duas brasileiras", porém os exercícios propostos restringem-se ao preenchimento de quadros e lacunas sobre informaçóes das duas mulheres e do uso do Pretérito Perfeito. Ao náo apresentar uma proposta que problematize essas duas situaçôes, corre-se o risco de uma simplificação e naturalização desses fatos.

No que concerne à figura 3, última imagem do volume 2, chama-nos atenção a representação do Brasil como a terra de samba, da alegria infinita, do gingado e da sensualidade da mulher.

\section{Figura 3 - Encerramento do Curso}

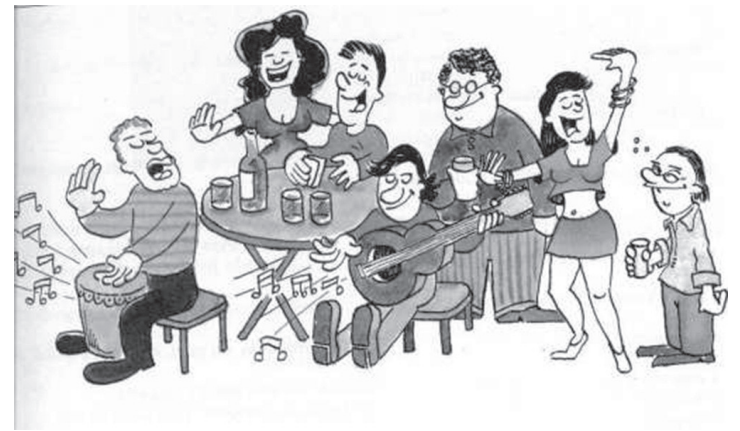

Fonte: Lima et al. (2006, v.2, p.109). 
Nessa imagem vemos cinco homens e duas mulheres, à volta de uma mesa, onde se vê copos e garrafas. Todos são brancos, com exceção do que toca tambor (o negro é minoria e está vinculado ao samba). A imagem sugere que as mulheres estáo dançando, uma delas com roupas que deixam parte de seu corpo à mostra. É possível depreender dessa ilustração o estereótipo da mulher brasileira e também do País onde tudo acaba em samba - frequentemente abordado pela mídia e guias turísticos.

O segundo livro que faz parte de nosso corpus é Bem-Vindo! A língua portuguesa no mundo da comunicação: Português para estrangeiros (2000). Este manual apresenta-se como um material elaborado para a aprendizagem da língua portuguesa tal como ela é falada no Brasil, deste modo, encontramos aí representadas expressóes coloquiais, diferenças regionais e um breve comentário sobre as diferenças de vocabulário entre o português falado no Brasil e em Portugal.

Em quatro unidades, há sessões específicas dedicadas à História do Brasil (subdivididas em "Do descobrimento à independência"; "Do Império à República"; "O Brasil Contemporâneo"; "Brasil: estabilidade econômica x estabilidade social"), onde são mostrados textos autênticos, na sua maioria.

É possível perceber um enfoque voltado para um trabalho com vocabulário, pois, ao final de cada página, o livro traz uma pequena lista de palavras, divididas por temas como: esportes, trânsito, vestuário, profissôes, frases populares, alimentos e outros considerados importantes no uso diário dos brasileiros. Além dessas listas de palavras, há sessões, em cada unidade, voltadas para especificamente para o vocabulário, sob o título de Vocabulário relevante, onde é elencado o léxico considerado importante naquela unidade. No item amplie seu vocabulário são apresentados textos que reforçam o tema trabalhado.

Em quatro unidades, há sessões dedicadas à História do Brasil (subdivididas em Do descobrimento à independência; Do Império à República; O Brasil Contemporâneo; Brasil: estabilidade econômica x estabilidade social), onde são mostrados textos autênticos, na sua maioria.

Ainda no que se refere aos aspectos culturais, o livro traz, nas quatro últimas unidades, um tópico denominado "Gente e cultura brasileira", no qual são abordados temas como "Literatura, Música" e os diferentes tipos regionais que formam o povo brasileiro: o caipira, o gaúcho, o sertanejo, o caboclo, o mulato, o pantaneiro, o mestiço oriental e outros. (Figuras 4 e 5). 
Figura 4 - Quem somos nós, afinal?(1)

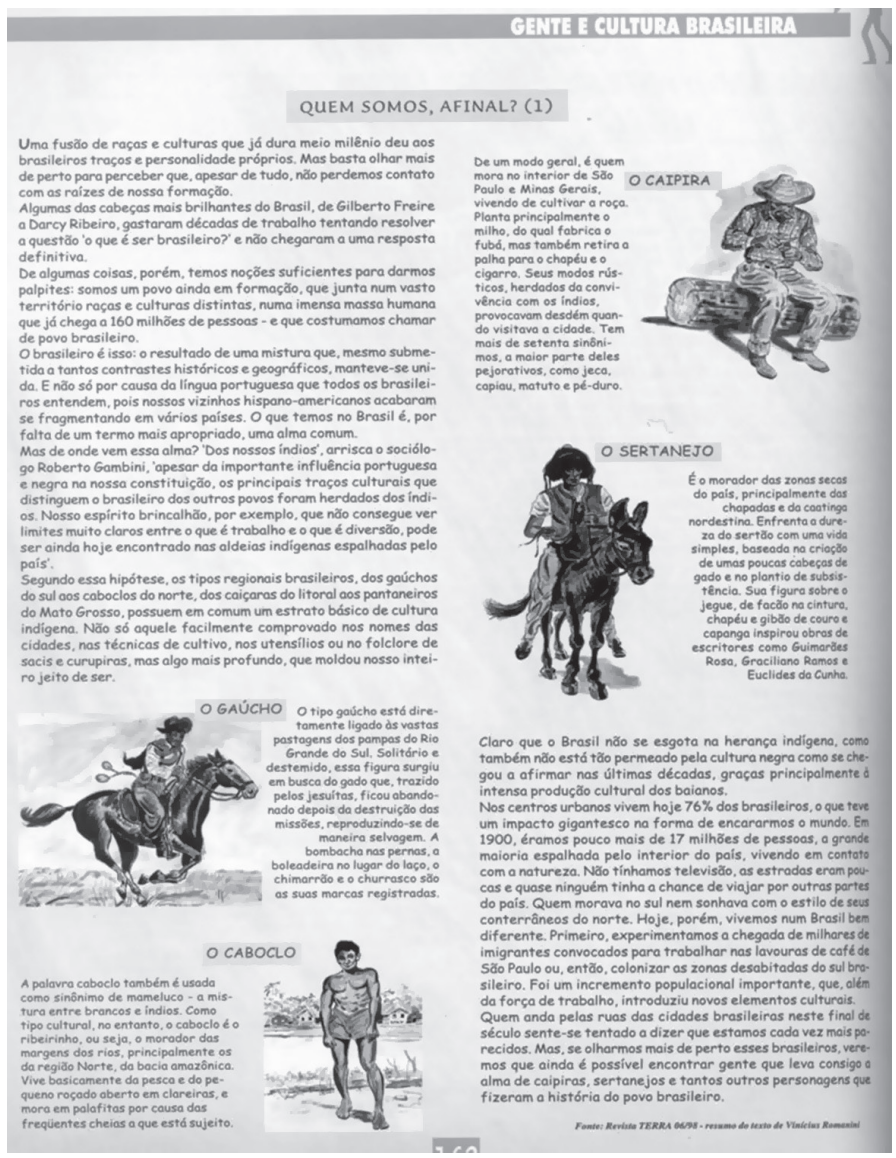

Fonte: Florissi, Ponce e Burim (2000, p.162).

A partir do título "Quem somos nós, afinal?", a unidade 17 inicia-se com uma explicação do povo brasileiro. O trecho é, conforme sublinhado, uma síntese de outro texto. Pode-se depreender das primeiras linhas que se trata de uma exaltação ao mito da democracia racial, com a caracterizaçáo de um País homogêneo, como mostra o excerto: "O brasileiro é isso: o resultado de uma mistura que, mesmo submetida a tantos constrastes históricos e geográficos, manteve-se unida." Essa unidade comparece na "língua portuguesa que todos os brasileiros entendem", embora saibamos da existência de 227 etnias indígenas com modos de organização sociais, econômicas e políticas diversificadas, que falam 180 línguas diferentes.

No excerto discursivo, vemos expostos estereótipos bastante difundidos de que, por exemplo, os povos indígenas não são afeitos ao trabalho e que deles herdamos essa aversão como uma característica. 
Figura 5 - Quem somos nós, afinal?(2)

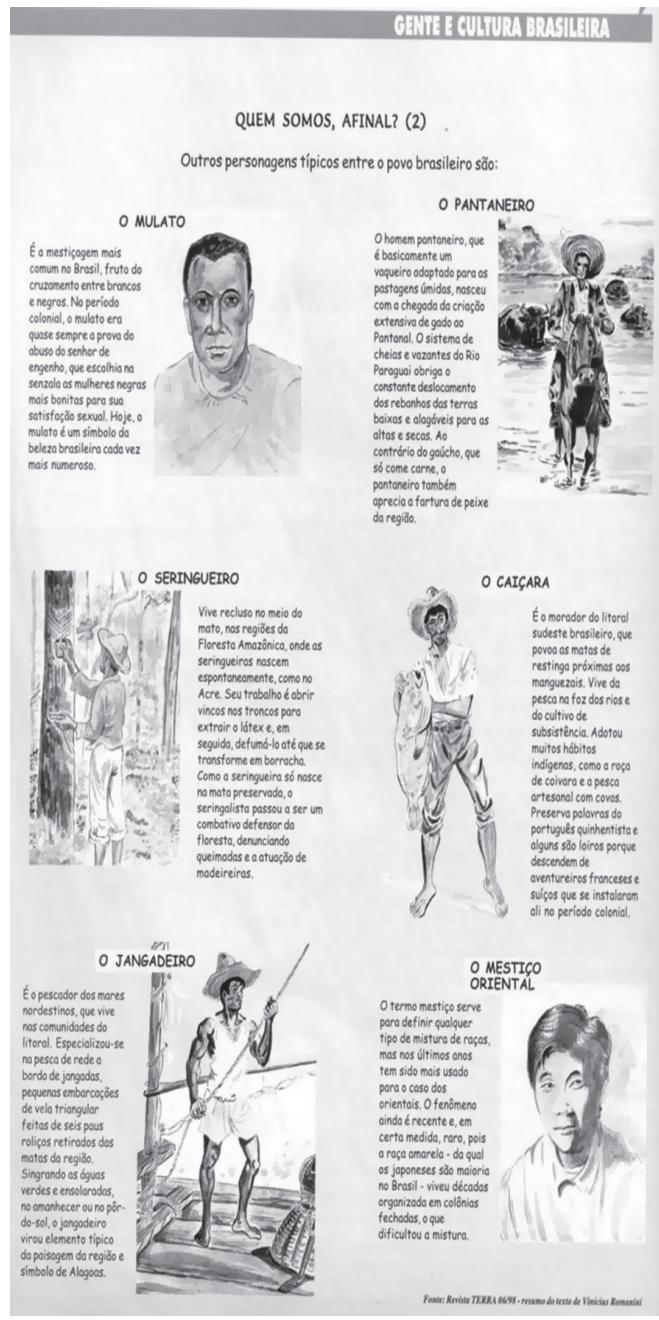

Fonte: Florissi, Ponce e Burim (2000, p.172).

Os dois textos prosseguem na caracterização (textual e iconográfica) dos chamados tipos brasileiros, cuja análise por si só merece um estudo à parte.

Observamos que este manual apresenta alguns tópicos relacionados a aspectos da cultura brasileira sob o título de "curiosidades", uma palavra que, no nosso entendimento não colabora para a inserção do aprendente a uma educação intercultural. Além disso, Byram (1992) assinala que a língua incorpora essencialmente os valores e as significaçóes de uma cultura, pois ela não apenas se refere a artefatos, mas diz respeito às identidades culturais dos indivíduos que compóem a sociedade. 


\section{Conclusão}

As observaçōes aqui apresentadas, de caráter exploratório, permitem-nos afirmar que o corpus escolhido apresenta uma quantidade significativa de informaçóes sobre aspectos culturais do Brasil e avaliamos que isso é um ponto positivo. No entanto, as análises efetuadas também mostram que os elementos sócio-culturais são trazidos para o livro apenas como adorno ou franja como assinala Almeida Filho (2002). Não se evidencia uma preocupação em passar uma imagem mais fiel das realidades brasileiras, com o objetivo de provocar no aprendente uma consciência crítica.

No que se refere à representação geral do País, constatamos que as imagens recorrentes são as associadas a aspectos turísticos do Brasil: praias (e tudo que elas evocam: férias, barquinhos, coqueiros), cachoeiras, pantanal, cidades coloniais, Rio de Janeiro, Cristo Redentor e Cataratas do Iguaçu. Tal escolha aproxima o livro didático do cartão postal, gênero textual com características e funçóes diferenciadas e específicas, nitidamente voltada ao turismo. Há que se ressaltar uma centralização de episódios que ligados a grandes centros, sobretudo ao eixo Rio-São Paulo, o que, no nosso entendimento, prejudica a imagem (ausente) de outras importantes cidades e regiôes brasileiras. A imagem de terra de samba, futebol e cordialidade também é frequentemente reforçada, sem a necessária crítica das apropriaçóes desses elementos socio-culturais nas diferentes realidades e culturas do Brasil.

A presença de escritores, cantores e compositores conhecidos internacionalmente denota preferência por uma cultura erudita do país em detrimento de culturas do cotidiano. Neste jogo de presença versus ausência, revela-se uma cultura estática, homogênea, por meio de um discurso-síntese, uma vez que o papel didático dessa iconografia é pouco ou nada trabalhado.

Concernente ao tratamento da diversidade étnico-racial, fica visível que nos dois manuais analisados, há um silenciamento em relação às populaçóes negras e indígenas. Além disso, as eventuais classificaçóes dos tipos brasileiros são cristalizadas e baseiam-se em contextos sociais, históricos, geográficos delimitados e demarcados.

Desse modo, a forma padronizada que o Brasil e os brasileiros são apresentados, no interior dos livros didáticos aqui brevemente analisados, opóe-se ao caráter dinâmico das culturas e aos movimentos e interpenetraçóes constantes pelos quais elas passam . A partir dessa perspectiva, língua e cultura não podem restringir-se ao caráter meramente informativos (ensina-se sobre língua-cultura), como observa Almeida Filho (2002). Ao privilegiar ilustraçóes ou curiosidades culturais que apenas acrescentam $a$, mas não compóem a competência linguístico-comunicativo-cultural desejada, dá-se margem para que o exotismo avance e constitua um impedimento de se estar socialmente naquela língua-cultura da qual se quer participar.

Um deslocamento desse olhar fixo no folclore, na curiosidade e nos estereótipos, pressupóe necessariamente admissão da heterogeneidade que tipifica qualquer grupo social. Além disso, um procedimento (ou uma açáo) intercultural visa agir sobre as 
atitudes e representaçóes a respeito da língua-cultura do Outro, a fim de possibilitar ao aprendente o desenvolvimento de sentimentos de relativização de suas certezas e de aceitação do Outro tal como ele se apresenta. Para que isso ocorra de forma refletida, é desejável que professore(a)s e autores(as) de livros didáticos revisem eventuais folclorizações que possam perpassar o ensino da língua-cultura. Essa postura pressupóe o reconhecimento das contradiçóes históricas que marcam os atores partícipes da sociedade que ajudam a construir. Tal postura, em lugar de diminuí-la, contribui a sua valorização e enaltecimento.

\section{INTERCULTURAL PROCEDURES AND BRAZIL'S ETHNIC-RACIAL DIVERSITY ON TWO PORTUGUESE FOR FOREIGNERS DIDACTIC BOOKS}

- ABSTRACT: In the present article we aim to discuss to what extent the concept of interculturality is present in two textbooks of Portuguese as a foreign language produced in Brazil, and how ethnic group participants of the Brazilian culture are characterized in them. Our guiding principle is the intercultural education that preconizes the development of comprehension and the acknowledgment not only of cultures in contact in the context of teaching and learning languages, but as well of the differences between them.

- KEYWORDS: Interculturality. Portuguese for foreigners. Textbook. Ethnic and racial diversity. Representation.

\section{REFERÊNCIAS}

ABDALLAH-PRETCEILLE, M. Compétence culturelle, compétence interculturelle: pour une anthropologie de la communication. Le Français dans le Monde, Paris, n. spécial, p.28-38, janv. 1996a.

. Vers une pédagogie interculturelle. Paris: Anthropos, 1996b.

ALMEIDA FILHO, J. C. P. de. Língua além de cultura ou além de cultura, língua? aspectos do ensino de interculturalidade. In: CUNHA, M. J. C.; SANTOS, P. Tópicos em Português língua estrangeira. Brasília: Ed. da UnB, 2002. p.209-215.

BARBOSA, L. M. A. Opacité et transparence lexico-culturelle dans l'apprentissage du Portugais Langue étrangère au Brésil: les paroles de chansons, instrument de médiation linguistique et culturelle. Lille: Atelier National de Reproduction des Thèses, 2008.

Concepção de língua e de cultura no ensino-aprendizagem de língua estrangeira. In: GATTOLIN, S. R. B.; MIOTELLO, V.; SIGNORI, M. B. D. Década: dez anos entre o aprender e o ensinar linguagens. São Carlos: Pedro e João Editores, 2007a. p.107-119. 
- La langue-culture et les dimensions interculturelles dans l'enseignement et l'apprentissage d'une langue culture étrangère. Ikala, Revista de Lenguaje y Cultura, v.1, p.165-181, 2007b.

BEACCO, J.-C. Les dimensions culturelles des enseignements de langue: des mots au discours. Paris: Hachette, 2000.

BOLOGNINI, C. Z. Livro didático: cartão postal do país onde se fala a língua-alvo? Trabalhos em Linguística Aplicada, Campinas, v.17, p.43-56, jan./jun. 1991.

BYRAM, M. Culture et éducation en langue étrangère. Paris: Credif, 1992.

COLLES, L. Interculturel: des questions vives pour le temps présent. Belgique: E.M.E, 2006.

DE CARLO, M. L'interculturel. Paris: CLE International, 1998.

GALISSON, R. En matière de culture le ticket AC - DI a-t-il un avenir? Études de Linguistique Apliquée, Paris, n.100, p.79-97, 1995a.

Où il est question de lexiculture, de Cheval de Troie et d'impressionnisme. Études de Linguistique Apliquée, Paris, n. 97, p.5-14. 1995 b.

FLORISSI, S.; PONCE, M. H. O.; BURIM, S. R. B. A. Bem-vindo! A língua portuguesa no mundo da comunicação: Português para estrangeiros. São Paulo: SBS, 2000.

FREYRE, G. Casa-grande e senzala. Rio de Janeiro: José Olympio, 1984.

HALL, E. T. La dimension cachée. Paris: Seuil, 1971.

LIMA, E. E. O. F. et al. Avenida Brasil: curso básico de Português para estrangeiros. São Paulo: EPU, 2006. 2v.

PORCHER, L. Programme, progrès, progressions, projets dans l'enseignement/apprentissage d'une culture étrangère. Études de Linguistique Appliquée, Paris, v.69, p.91-100, 1988.

La civilisation. Paris: CLE International, 1986.

ZARATE, G. Enseigner une culture étrangère. Paris: Hachette, 1986. 